Western University

Scholarship@Western

FIMS Publications

Information \& Media Studies (FIMS) Faculty

2014

Changing Chance Encounters: Historians, Serendipity, and the Digital Text

Kim Martin

Western University

Anabel Quan-Haase

The University of Western Ontario, aquan@uwo.ca

Follow this and additional works at: https://ir.lib.uwo.ca/fimspub

Part of the Library and Information Science Commons

Citation of this paper:

Martin, Kim and Quan-Haase, Anabel, "Changing Chance Encounters: Historians, Serendipity, and the Digital Text" (2014). FIMS Publications. 78.

https://ir.lib.uwo.ca/fimspub/78 


\title{
CAIS Paper: Changing Chance Encounters: Historians, Serendipity, and the Digital Text
}

Kim Martin (University of Western Ontario) and Anabel Quan-Haase (University of Western Ontario)

\begin{abstract}
:
Twenty academic historians in Southern Ontario were interviewed about their use of e-books and the role of serendipity in their research. A central theme that surfaced from the grounded theory analysis was that their use of digital tools and texts is limiting their opportunity for a chance encounter with information.
\end{abstract}

Resume:

\section{Introduction}

The use of digital tools and the impact they have on humanistic research is an important area of scholarship. As the growing area of the digital humanities moves into the mainstream, it is important for scholars to recognize the changes in the information behavior of humanities scholars.

One aspect of particular relevance is the interrelation between electronic tools and serendipity. Serendipity is generally understood as the chance encounter with information (Erdelez 2004), which leads toward a fortuitous outcome or new insight (Rubin, Burkell, and Quan-Haase 2011; Makri and Blandford 2012a). Serendipity has consistently been shown to play an important role in scientific discoveries, and has also been shown to be essential in the scholarship of humanists (Duff and Johnson 2002; Hoeflich 2007; McClellan III 2005).

The aim of the present study is to examine the ways that historians conduct their research in both physical and digital environments. Research questions to be addressed are:

1. How important is the physical library with regards to serendipity as it is experienced by historians?

2. What search and browsing capabilities does the digital format provide for historians that might not be possible in the stacks?

3. Are electronic tools potentially changing the nature of scholarly work, the types of insights made by scholars, and how information is garnered? Or are the changes rather minor and incremental?

\section{Literature Review}

Despite an increased interest in the information environment of humanists, few studies have examined the extent to which the reliance on digital tools affects scholars' ability to seek and encounter information. A number of studies have surfaced investigating the types of electronic tools that humanists use in their research and teaching (Toms and O'Brien 2008), their perceptions toward the use of these tools (Barrett 2005), and their willingness to adopt new electronic tools in their scholarship and teaching (Tahir, Mahmood, and Shafique 2010).

Scholars have repeatedly found that one of the important aspects of the library to humanists is the possibility of a serendipitous find (Case 1991; Delgadillo and Lynch 1999; Hoeflich 2007; Martin and Quan-Haase 2013). Stone (1982) remarked that although this trait was often mentioned in relation to humanists, it was a hard concept to study. Serendipity is often perceived as an ephemeral phenomenon, which is difficult to distinguish from other kinds of encounters with information, such as browsing or information gathering. Nonetheless, evidence from studies in the humanities exists as to the relevance of the concept. Serendipity in a library is most often described as occurring when the scholar goes to the shelves to look for books, journals, magazines, or archival records and comes across a source other than the one for which they were searching. Budd (1989) argues that the importance that humanists place on searching for information and the fact that serendipity in their work is "not only inevitable but desirable" (p. 9) is one reason that these scholars depend so heavily on the 
library as a physical place. Humanist scholars themselves have written on the ways that their work has been affected by a chance encounter with material. Hoeflich (2007), for example, compares historians to "ancient mariners", who "set out upon uncharted paths in libraries and archives, never really knowing what [they] will find" (p. 213).

Scholars from different fields have commented on how serendipity plays a role in the research process (André et al. 2009; Campos and Figueiredo 2002; Cooksey 2004; van Andel 1994). For instance, scientists have shown the importance of having an open and creative mind during the scientific process and how discovery of findings can occur when proper connections are noticed and acted upon (Barber and Fox 1958). There have been many attempts in the past decade to investigate the notion of serendipity, how one experiences it, and if there are ways in which this experience can be fostered. In the field of library and information studies alone, researchers have looked at blogs (Rubin, Burkell, and Quan-Haase 2011), scholars' work practices (Makri and Blandford 2012a; Makri and Blandford 2012b; Martin and Quan-Haase 2013), library catalogs (Race 2012), and web searching (Erdelez 2004) in order to explore the phenomenon of the chance encounter. More recently, scholars have proposed various models of serendipity to gain insight into how the phenomenon occurs and what facets or processes are involved. The following section represents our theoretical framework and outlines the key aspects of these models.

\section{Theoretical Framework}

There have been multiple attempts by library and information scientists to model the phenomenon of serendipity. Foster and Ford (2003) focused in their research on a group of interdisciplinary scholars. They applied grounded theory to a set of interview transcripts and concluded that serendipity had two main impacts on the researcher: "(1) by reinforcing or strengthening the researcher's existing problem conception or solution; or (2) by taking the researcher in a new direction, in which the problem conception or solution is re-configured in some way" (p. 330).

Rubin, Burkell, and Quan-Haase (2011) created a new model of serendipity after conducting a grounded theory study on blogs. They used Google Blog Search to selectively mine the results of publicly available blogs with 44 queries that were created to retrieve the instance of a chance encounter. Analysis of the blogs returned a total

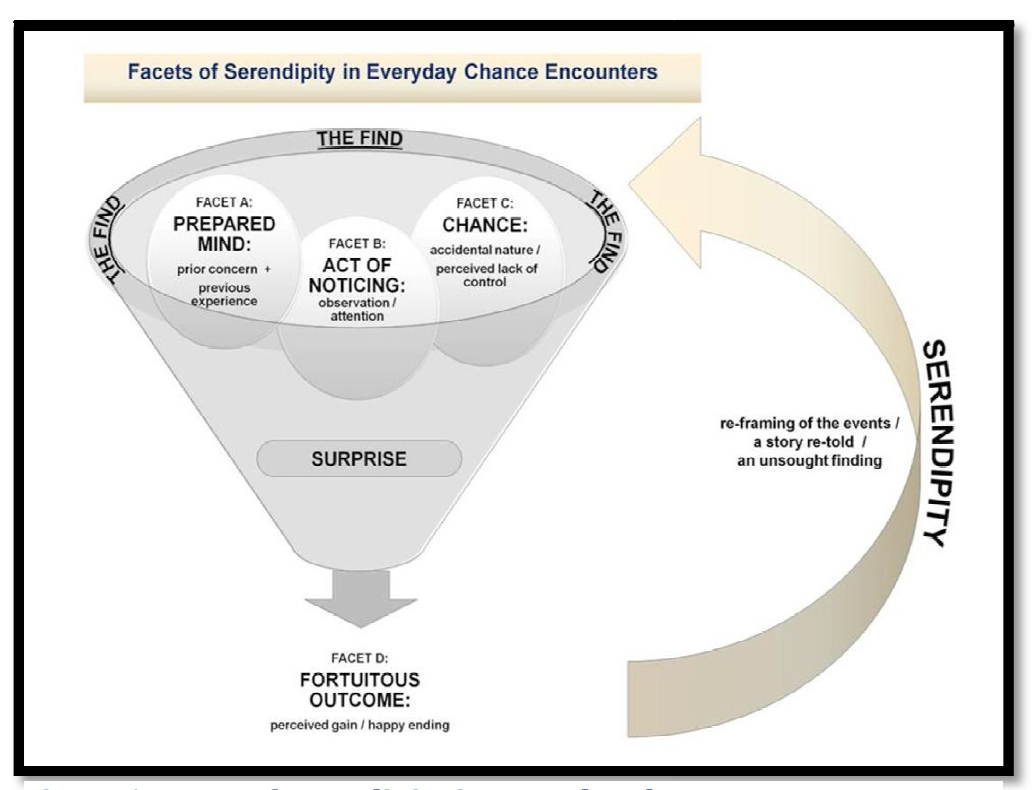

of 56 accounts of serendipity as defined by the authors. The authors then analyzed these accounts via grounded theory, applying three types of coding (open, axial, and selective) that led to the results: a set of emergent categories or 'facets' of serendipity. Their model (Figure 1) and the seven facets of serendipity that they outline are:
1) Prepared mind
2) Prior concern
3) Previous experience or expertise
4) Act of noticing
5) Fortuitous outcome
6) The find [and]
7) Surprise

Figure 1 Facets of serendipity in everyday chance encounters

(Rubin et al. 2011)

The model provided by these authors is unique in that it shows that serendipity is no longer simply a linear process, but is one that requires certain elements to come together to create a fortuitous outcome.

The second theoretical framework that informs our work is affordances of technology. The concept of affordances originally was developed in psychology by Donald Norman to explain how objects can elicit specific behaviors (Norman 1988). The best example is that of a doorknob that invites individuals to open a 
door. The concept of affordances has been utilized also to understand the complexities of human-computer interaction (HCI). For instance, Bradner et al. (2001) used it to understand collaborative behavior in an online system, where the system affords certain social behaviors as a result of its design. We draw on the concept of affordance in this study to better understand how digital and physical environments support different aspects of serendipity.

\section{Methods}

The study employed semi-structured interviews as its data collection method. Overall, 20 interviews lasting about 30 to 60 minutes were conducted with history faculty and graduate students at institutions of higher education in Southern Ontario from October 2010 to May 2013. Semi-structured interview questions allowed participants to respond in their own words and enabled the interviewer to probe responses and open new avenues for discussion (Berg 2005).

We utilized grounded theory and in particular line-by-line coding because this approach allows for the development of new insights based on the data itself. After we had developed a full list of in vivo codes on the topic, several themes emerged (see Figure 2).

\begin{tabular}{|c|c|c|c|}
\hline Physical Searching & $\begin{array}{l}\text { Accidental } \\
\text { Information } \\
\text { Acquisition }\end{array}$ & $\begin{array}{l}\text { Affordances of } \\
\text { Digital Search }\end{array}$ & $\begin{array}{l}\text { Heuristic } \\
\text { Serendipity }\end{array}$ \\
\hline $\begin{array}{l}\text {-go through } \\
\text {-wade through } \\
\text {-searching } \\
\text { - looking } \\
\text {-seeing } \\
\text {-stumbles } \\
\text {-scans } \\
\text {-picking it up } \\
\text {-flipping through }\end{array}$ & $\begin{array}{l}\text {-stumble upon } \\
\text {-inadvertant } \\
\text { - discovery } \\
\text { - all of a sudden } \\
\text { - accident } \\
\text { - serendipity } \\
\text { - weren't looking for }\end{array}$ & $\begin{array}{l}\text {-drill through info } \\
\text { targeted } \\
\text { efficient } \\
\text { keyword } \\
\text { scroll usability }\end{array}$ & $\begin{array}{l}\text { - play around } \\
\text { - respond to } \\
\text {-recommendation } \\
\text { - browsing tool } \\
\text { - order } \\
\text { - teach } \\
\text { - catalog }\end{array}$ \\
\hline
\end{tabular}

Figure 2 Preliminary in vivo codes and conceptual themes

\section{Findings and Discussion}

Historians in the present study have started to use e-books because of their benefits to scholarship and teaching, such as keyword searching, portability, ease of access, fact-checking and convenience (Martin and Quan-Haase 2013). However, none of the participants indicated that they would use e-books for researching a topic at length due to the restrictive nature of the search functions and the limitations of the digital tools associated with ebooks. Six of the twenty participants indicated that they will continue to go to the physical library to search and browse for information until their traditional research methods, including the element of serendipity could be recreated or replaced in the digital realm. Four main themes surrounding chance information encountering emerged from the interviews. The following sections elaborate on these themes and detail how they link to historian's information behavior.

1. Importance of the physical library experience: When asked about the role of serendipity in their research, 15 of the 20 participants spoke of being in the physical library. For them, the library is where the chance encounter with information was most likely to occur (Stone 1982). In general, a distraction from the task at hand occurred when they noticed something "they weren't looking for" [P3] and discovered ways in which this item was linked to their current search, or another topic of interest. 
2. Affordances of digital search: While the physical library was the preferred place for searching and browsing for material, several of the historians made note of the advantages of searching online. Keyword searching, although linked to targeted searches that limited the chance encounter, was still noted as beneficial for searching by seven of the participants.

The efficiency of digital searching was remarked upon by six of the scholars. One faculty member noted that his students' searches were likely to be more thorough than those of previous generations because the digital allows users to find things that would not have turned up in a physical search: "It allows them to cast their net more broadly and allows them to find stuff that maybe in a conventional hard copy search they might not have found" [P3].

3. Changing chance encounters: The participants indicated a definite anxiety over changes to their traditional research processes if historians made the move to e-books. The primary concern of participants is that search engines and digital documents allow for quick retrieval of targeted information, and scholars who make use of them are less likely to browse information, and therefore are less likely to come across anything by chance. This supports the findings of previous information seeking models that outline the importance of browsing to the information seeking of researchers (Ellis 1993; Wilson 1999).

4. Introducing new "heuristic" forms of serendipity: Despite these anxieties, over half of the participants were curious about e-books and how the technology could aid their teaching and research. Seven participants indicated that they were willing to experiment with e-books and hoped that serendipity might be built back into these digital systems, whether via a recommendation system or a digital browsing tool.

\section{Conclusions and Future Work}

As the move towards the digital continues, it is likely that historians involved in this shift will work with both physical and digital documents, taking full advantage of the affordances of both of these environments. We coin the term environment suitability to describe how historians determine what environments-digital or physicalsuits a specific task. While historians do not consciously think about serendipity when choosing between digital and physical environments, rather consider factors such as convenience, speed, and familiarity, the lack of serendipity is perceived as a major problem in digital environments. The facets of serendipity such as "act of noticing" and "fortuitous outcome" as recognized by Rubin et al. (2011) are reiterated in the historians' interviews about their research habits. The serendipitous encounter with information will continue to be an element of their research process, though the distractions noticed and the connections made will differ depending on whether the search is conducted in the library stacks or via a catalogue browser. Information professionals must be aware of the pros and cons of both of these environments in order to develop tools and systems that complement each other. Although digitization changes the ways in which scholars encounter information, it is no longer considered an obstacle for all historians. As more interest in digitized sources widens, and as the number of documents found online grows, it is likely that historians will develop new, more creative ways to encounter information. Participants voiced a call for non-invasive, inconspicuous tools that facilitate their work through serendipity.

\section{References}

André, Paul, M C Schraefel, Jaime Teevan, and Susan T Dumais. 2009. "Discovery Is Never by Chance: Designing for ( Un ) Serendipity.” In Knowledge Creation Diffusion Utilization C\&C '09. Berkeley, CA: ACM.

Barber, Bernard, and Renee C. Fox. 1958. "The Case of the Floppy-Eared Rabbits : An Instance of Serendipity Gained and Serendipity Lost .” American Journal of Sociology 64 (2): 128-136.

Barrett, Andy. 2005. "The Information-Seeking Habits of Graduate Student Researchers in the Humanities." The Journal of Academic Librarianship 31 (4) (July): 324-331. doi:10.1016/j.acalib.2005.04.005. 
Berg, B.L. 2005. Qualitative Research Methods (5th Edition). Boston Mass.: Pearson.

Bradner, E. 2001. "Social Affordances of Computer-Mediated Technology: Understanding Adoption.” In CHI 'O1 Extended Abstracts on Human Factors in Computing, 67-68. ACM.

Budd, John M. 1989. "Research in Two Cultures: The Nature of Scholarship in Science and the Humanities." Collection Management 11 (3/4): 1-19.

Campos, José, and A Dias De Figueiredo. 2002. "Programming for Serendipity.” Artificial Intelligence.

Case, D O. 1991. "The Collection and Use of Information by Some American Historians: A Study of Motives and Methods." The Library Quarterly 61 (1): 61-82. doi:10.1086/602298.

Cooksey, Elizabeth B. 2004. "Too Important to Be Left to Chance - Serendipity and the Digital Library." Science \& Technology Libraries 25 (1): 23-32. doi:10.1300/J122v25n01.

Corbin, Juliet, and Anselm Strauss. 2008. Basics of Qualitative Research: Grounded Theory Procedures and Techniques. Newbury Park, CA: Sage Publications.

Delgadillo, Roberto, and Beverly P Lynch. 1999. "Future Historians : Their Quest for Information." College \& Research Libraries 60 (3): 245-259.

Duff, Wendy M, and Catherine A Johnson. 2002. “Accidentally Found on Purpose: Information-Seeking Behavior of Historians in Archives." The Library Quarterly 72 (4): 472-496. doi:10.2307/40039793.

Ellis, David. 1993. "Modeling the Information-Seeking Patterns of Academic Researchers : A Grounded Theory Approach.” The Library Quarterly 63 (4 Symposium on Qualitative Research : Theory , Methods , and Applications): 469-486.

Erdelez, Sanda. 2004. "Investigation of Information Encountering in the Controlled Research Environment." Information Processing \& Management 40 (6) (November): 1013-1025. doi:10.1016/j.ipm.2004.02.002.

Foster, Allen, and Nigel Ford. 2003. "Serendipity and Information Seeking: An Empirical Study." Journal of Documentation 59 (3): 321-340. doi:10.1108/00220410310472518.

Hoeflich, Michael H. 2007. "Serendipity in the Stacks, Fortuity in the Archives *." Law Library Journal 99 (4): 813-827.

Makri, Stephann, and Ann Blandford. 2012a. "Coming Across Information Serendipitously - Part 1: A Process Model.” Journal of Documentation 68 (5): 684-705.

. 2012b. "Coming Across Information Serendipitously : Part 2 - A Classification Framework." Journal of Documentation 68 (5): 706-724.

Martin, Kim, and Anabel Quan-Haase. 2013. “Are E-Books Substituting Print Books? Tradition, Serendipity, and Opportunity in the Adoption and Use of E-Books for Historical Research and Teaching." Journal of the American Society for Information Science and Technology 64 (5): 1016-1028.

McClellan III, James E. 2005. "Accident, Luck, and Serendipity in Historical Research.” Proceedings Of The American Philosophical Society 149 (1): 1 - 21.

Norman, D. A. 1988. The Psychology of Everyday Things. New York N.Y.: Basic Books.

Race, Tammera M. 2012. "Resource Discovery Tools : Supporting Serendipity Planning and Implementing Resource Discovery Tools in Academic Libraries.” DLTS Faculty Publications Paper 22. 
Rubin, V.L., J. Burkell, and Anabel Quan-Haase. 2011. “"Facets of Serendipity in Everyday Chance Encounters: a Grounded Theory Approach to Blog Analysis." Information Research 16 (3).

Stone, Sue. 1982. "Humanities Scholars: Information Needs and Uses.” Journal of Documentation 38 (4): $292-$ 313.

Tahir, Muhammad, Khalid Mahmood, and Farzana Shafique. 2010. "Use of Electronic Information Resources and Facilities by Humanities Scholars." The Electronic Library 28 (1): 122-136. doi:10.1108/02640471011023423.

Toms, Elaine G., and Heather L. O’Brien. 2008. "Understanding the Information and Communication Technology Needs of the e-Humanist." Journal of Documentation 64 (1): 102-130. doi:10.1108/00220410810844178.

Van Andel, Pek. 1994. "Anatomy of the Unsought Finding. Serendipity: Origin, History, Domains, Traditions, Appearances, Patterns and Programmability.” British Journal of Philosophical Science 45: 631-648.

Wilson, T D. 1999. “Models in Information Behaviour Research.” Journal of Documentation 55 (3): $249-270$. 